\title{
Cognitive and affective outcomes of genetic counselling in the Netherlands at group and individual level: a personalized approach seems necessary
}

\author{
Jan S. Voorwinden ${ }^{1} \cdot$ Mirjam Plantinga ${ }^{2} \cdot$ Margreet Ausems $^{3} \cdot$ Nine Knoers $^{2} \cdot$ Mary Velthuizen $^{3} \cdot$ Erwin Birnie $^{2} \cdot$ \\ Anneke M. Lucassen $\mathbb{1}^{4} \cdot$ Adelita V. Ranchor ${ }^{1} \cdot$ Irene M. van Langen ${ }^{2}$
}

Received: 24 September 2019 / Revised: 13 March 2020 / Accepted: 24 March 2020 / Published online: 27 April 2020

(c) The Author(s), under exclusive licence to European Society of Human Genetics 2020

\begin{abstract}
We performed a large outcome study at group and individual level in which the goals of genetic counselling were operationalized into cognitive and affective outcomes: empowerment, perceived personal control and anxiety. We then examined which socio-demographic and clinical variables were associated with changes in these outcomes. Data came from 1479 counselees who completed questionnaires (GCOS-18, PPC and STAI) at three time points: before the start of genetic counselling, after the first consultation and after the results of genetic counselling were disclosed. Results showed that at group level empowerment, perceived personal control and anxiety improved significantly after the whole genetic counselling process. Effect-sizes were medium for empowerment and small for the other outcomes. At individual level, $48 \%$ of counselees improved in empowerment, $21 \%$ in perceived personal control and $17 \%$ in anxiety. Around $10 \%$ of counselees worsened on all outcomes. Only 'reason for referral' and 'genetic test result' were significantly associated with changes in outcomes. This study demonstrated improvements among counselees in cognitive and affective outcomes after genetic counselling at group level. However, our results also suggest that there are opportunities for improvement at individual level, as many counselees remained stable and some even worsened on all outcomes. Routine outcome monitoring could help to explore the needs of counselees and could help to identify counselees who worsen.
\end{abstract}

\section{Introduction}

In the last decades many studies have been published examining the outcomes of genetic counselling within groups of counselees from different backgrounds and applying different

Supplementary information The online version of this article (https:// doi.org/10.1038/s41431-020-0629-5) contains supplementary material, which is available to authorized users.

Jan S. Voorwinden

j.s.voorwinden@umcg.nl

1 Department of Health Psychology, University Medical Center Groningen, University of Groningen, Groningen, the Netherlands

2 Department of Genetics, University Medical Center Groningen, University of Groningen, Groningen, the Netherlands

3 Department of Genetics, University Medical Center Utrecht, University of Utrecht, Utrecht, the Netherlands

4 Faculty of Medicine, Department of Clinical Ethics and Law, University of Southampton, Southampton, UK questions [1-3]. However, it is still unknown whether the theoretically formulated, commonly shared, professional goals of genetic counselling are achieved, and if so, for whom and why. With this study we hope to contribute to the evidence-based knowledge on these topics with the aim of improving the counselling process.

Genetic counselling is defined as "the process of helping people understand and adapt to the medical, psychological and familial implications of genetic contributions to disease" [4]. This definition is based on consensus among genetic professionals. A definition helps to clarify the goals of genetic counselling as they dictate practice [4]. The goals of genetic counselling focus on meeting clients' needs, usually by providing genetic education and psychosocial support [5]. To evaluate genetic counselling, these educational and support goals can be operationalized into patient outcomes. Educational goals are often measured as cognitive outcomes (such as knowledge, perceived risk or perceived personal control), while the outcomes of psychosocial support are often measured as affective outcomes (anxiety, depressive symptoms, distress or worries) [6]. 
It can be difficult to compare findings across studies because researchers have used disparate patient-reported outcome measures (PROMs) to evaluate the same outcomes [3]. Moreover, many PROMs do not combine cognitive and affective outcomes, making them less applicable for monitoring routine outcomes in clinical practice. In addition, most instruments are not specifically designed for the genetic counselling setting, so they may not focus sufficiently on its educational and supportive goals. To improve the comparability of outcome studies in genetic counselling, a validated, internationally accepted PROM is necessary, that includes both cognitive and affective outcomes, and that is specifically developed for the setting of genetic counselling.

A construct that contains both cognitive and affective outcomes is 'empowerment'. Empowerment has been defined as a combination of cognitive, decisional and behavioural control, emotional regulation and hope [7]. Empowerment has been identified as a key patient outcome goal of genetic counselling and may therefore be a useful overarching construct that represents many PROMs in clinical genetics services [8]. McAllister et al. developed a 24-item questionnaire measuring empowerment in the setting of genetic counselling, the Genetic Counselling Outcome Scale (GCOS) [7], and we recently validated the Dutch version of this scale [9].

Another point of consideration is how outcomes are discussed. Outcomes are usually presented at group level [1-3], which may mask individual differences in change scores that reveal clinically important information. Given that some counselees may remain stable or even worsen on cognitive and affective outcomes after genetic counselling, only presenting outcomes at group level prevents analysis of how many and which counselees really benefit from genetic counselling. This approach also fails to highlight which people do not benefit from the current process, and why, knowledge critical to improving current clinical care. To understand more about outcomes of genetic counselling, we need to explore outcomes, as well as their determinants, at an individual level.

The aims of this study are threefold. We sought to: (1) measure cognitive and affective outcomes of genetic counselling at group level for a large and diverse Dutch study sample, (2) examine changes on these outcomes during the genetic counselling process at individual level, and (3) examine which socio-demographic and clinical variables are associated with these changes.

\section{Materials and methods}

\section{Participants}

This multicenter study included counselees from the Department of Genetics of the University Medical Center
Groningen and the Department of Genetics of the University Medical Center Utrecht. Participants had been referred by their general practitioner, medical specialist or midwife to one of these two centers for genetic counselling. Participants were eligible for inclusion if they had sufficient understanding of the Dutch language. If children were referred ( $<16$ years of age), their parents were considered the counselees, and one of the parents was asked to complete the questionnaires from her/his perspective. Referrals included counselees with a possible genetic condition, counselees referred for pre-symptomatic genetic counselling, and parents of referred children (with a possible genetic condition and pre-symptomatic). All 'pathogenic' variants in this study are in the context of an index patient and/or family with the condition caused by this variant, also known as 'class 4 and 5' variants [10]. Genetic counselling was provided by clinical geneticists and genetic counsellors specialized in different types of conditions: onco-genetics (mostly breast cancer, ovarian cancer and colorectal cancer), cardio-genetics (mostly cardiomyopathies and cardiac arrhythmias), neuro-genetics (mostly epilepsy, movement disorders, neurodegenerative diseases and muscular diseases), and 'general' (including intellectual disabilities, congenital syndromes, prenatal pathology and hereditary diseases that were not captured by the other teams, such as deafness and cystic fibrosis). Ethical approval for this study was granted by the Medical Ethical Review Committee of the University Medical Center Groningen (M13.139274).

\section{Study design and procedure}

This study has a pre-post observational design. Participants were included from September 2014 until February 2016. All counselees received a starting package sent to their home address that included an information letter about the study, an invitation letter for a first consultation at the hospital, an informed consent form and the first questionnaire (T0). Participants who gave consent received a second questionnaire (T1) the week after their first consultation and a third questionnaire (T2) within one week after their final consultation, where the results of genetic counselling were (often) discussed. In most cases two consultations were sufficient to answer a counselee's question(s). The second consultation was sometimes carried out by telephone or web-consultation, and in some cases no second consultation was needed. Afterwards, all counselees received a summarizing letter. A subgroup of counselees did not undergo DNA-testing. Their questions were answered after review of the pedigree and/or physical examination. Some counselees choose not to be tested (yet). The time between invitation letter and the first consultation was around 2 weeks. The time between the first consultation and result disclosure was a few weeks for carrier testing and 
around 3-6 months for index patients in whom genetic testing was performed.

\section{Measurement instruments}

Empowerment was measured with the validated Dutch version of the Genetic Counselling Outcome Scale (GCOS-18) [9]. The GCOS-18 consists of 18 items on a 7-point scale. Items 4, 5, 10, 11, 12, 17, 18 and 21 need reversion. The total score is calculated by adding the item scores (range 18-126), with a higher score indicating more empowerment. The internal consistency for our study sample was Cronbach's $\alpha$ 0.77-0.82.

Perceived personal control was measured with the validated Dutch version of the Perceived Personal Control questionnaire (PPC) [11]. The PPC consists of 9 items on a 3 -point scale. A total score is calculated by adding the item scores and dividing the total score by the total number of items (range 0-2), with higher scores indicating more control. The internal consistency for our study sample was Cronbach's $\alpha$ 0.81-0.85.

Anxiety was measured with the validated Dutch version of the short form of the state scale of the Spielberger StateTrait Anxiety Inventory (STAI) [12]. The STAI consists of six items on a 4-point scale. The total score is calculated by adding the item scores (range 6-24), with higher scores indicating more anxiety. A score $\geq 12$ is considered clinically elevated anxiety [13]. The internal consistency for our study sample was Cronbach's $\alpha 0.87-0.88$.

\section{Statistical analysis}

For missing data, case mean substitution was used as imputation strategy for respondents who met specific requirements (at least $80 \%$ of the items of a scale needed to be answered). Counselees who completed all three questionnaires were included in the analysis so that one fixed group of counselees could be followed across the whole genetic counselling process. To check if adjustment of confounders were necessary, included participants were compared with all respondents on socio-demographic, clinical and outcome variables at T0. Chisquare tests were used for categorical variables and $T$-tests for continuous variables. Differences were checked for statistical significance $(p<0.05)$.

Results were analysed for the total sample and by reason for referral (counselees with a possible genetic condition, counselees referred for pre-symptomatic genetic counselling and parents of referred children). A MANOVA was used to measure if outcomes changed significantly after the whole genetic counselling process (T0-T2) and if changes on outcomes differed significantly between subgroups. The dependent variables in these analyses were the GCOS-18, PPC and STAI. The $p$-values of the MANOVA were adjusted with Bonferroni correction for the number of outcome measures, resulting in a significance level of $p<$ 0.02 . Significant results were analysed further with planned contrasts (repeated) to measure changes on outcomes between sessions (T0-T1, T1-T2). These changes were checked for statistical significance $(p<0.05)$ and effect-size (Cohen's $d$ ). An effect-size of 0.2 is considered small, 0.5 medium and 0.8 large [14].

Next we examined change scores at an individual level for each outcome measure. The sample was stratified into three groups that distinguished between counselees who improved, those who remained stable, and those who worsened on outcomes. A cut-off of $0.5 \mathrm{SD}$ was used for classification because it is commonly regarded as the minimal clinical relevant change [15]. Counselees with change scores that improved more than $0.5 \mathrm{SD}$ were considered 'improved', while counselees with change scores worsening more than $0.5 \mathrm{SD}$ were considered 'worsened'. Counselees with change scores that improved or worsened less than $0.5 \mathrm{SD}$ were considered 'stable'.

Finally, these groups were compared on baseline values, socio-demographic and clinical variables. Continuous variables were measured with a one-way independent ANOVA. Categorical variables were measured with a Chi-square test. The $p$-values of the ANOVA and Chi-square tests were adjusted with Bonferroni correction for the number of independent variables, resulting in a significance level of $p<0.007$. Significant results were analysed further with post hoc tests (Bonferroni) or additional Chi-square tests to examine significant results in detail. All statistical analyses were carried out with IBM SPSS Statistics 23.

\section{Results}

\section{Sample}

In all, 5300 counselees were invited to participate, and 2502 completed T0 (47\%). After the first consultation, 1956 completed T1 (37\%). After the results of genetic counselling were disclosed, 1599 completed T2 (30\%). Of the 2502 participants, 1479 (59\%) completed all three questionnaires, and only these participants are included in this study. These 1479 participants consisted of 594 counselees with a possible genetic condition, 709 counselees referred for presymptomatic genetic counselling and 176 parents of referred children (167 children with a possible genetic condition and 9 referred for predictive genetic testing).

First, included participants were compared with all respondents (including counselees who did not complete all three questionnaires) at T0 to check if adjustment of confounders were necessary. Included participants were significantly older $(M=50.75, \mathrm{SD}=14.84$ vs. $M=47.70$, 
$\mathrm{SD}=14.90, t(3960)=-6.24, p<0.001)$. There were also significant differences in type of disease $\left(\chi^{2}(3)=8.93, p=\right.$ $0.030)$. Included participants were more often counselled for hereditary cancer $(54.6 \%$ vs. $51.0 \%)$ and less often counselled for 'other type' of diseases (13.5\% vs. $16.6 \%)$. There were no significant differences on all outcome variables between these groups. Therefore adjustment of confounders were considered unnecessary.

Second, the socio-demographic and clinical variables of the included participants were measured for the total sample and by reason for referral (see Table 1). Variables differed significantly between subgroups. Parents of referred children were more often younger, female, higher educated and being counselled for neuro-genetic and 'other' type of diseases. Counselees with a possible genetic condition and counselees referred for pre-symptomatic genetic counselling were more often counselled for the onco-genetic and cardiogenetic types of diseases. Genetic testing more often identified a pathogenic variant among children with a genetic condition than among adults with a genetic condition. As the outcomes of these subgroups were studied separately, adjustment of confounders for these differences were considered unnecessary.

\section{Aim 1: all outcomes of genetic counselling improved at group level}

Table 2 shows the outcomes of genetic counselling for the total sample. After the whole genetic counselling process (T0-T2), there were significant improvements in empowerment $(V=0.22, F(2,1415)=197.14, p<0.001)$, perceived personal control $(V=0.03, F(2,1405)=24.76$, $p<.001)$ and anxiety $(V=0.04, F(2,1426)=32.24, p<$ $0.001)$. Effect-sizes were medium for empowerment and small for the other outcomes. Contrast analyses were then used to analyse the effects on outcomes per session. After the first consultation (T0-T1), all outcomes improved significantly and effect-sizes were small for all outcomes. After the results of genetic counselling were disclosed (T1-T2), empowerment and anxiety improved significantly and effect-sizes were small for both outcomes, while perceived personal control did not change significantly during this period.

Table 2 shows also the outcomes of genetic counselling by reason for referral. Changes in outcomes did not differ significantly between counselees with a possible genetic condition, counselees referred for pre-symptomatic genetic counselling and parents of referred children on empowerment $(V=0.01, F(4,2832)=1.67, p=0.154)$ and anxiety $(V \leq 0.01, F(4,2838)=0.48, p=0.748)$. However, there were significant differences between these subgroups on perceived personal control $(V=0.02, F(4,2812)=5.26$, $p<0.001)$. After the results of genetic counselling were discussed (T1-T2), perceived personal control only improved significantly among parents of referred children.

\section{Aim 2: changes at an individual level showed large differences between counselees on all outcomes}

Figure 1 shows graphs with the percentages of counselees who improved, remained stable and worsened on each outcome based on individual change scores. Descriptive information about these clustered individual change scores is shown in Table S1 (Supplementary Information).

After the first consultation (T0-T1), 35\% of counselees improved on empowerment, with fewer counselees improving on perceived personal control (16\%) and anxiety (10\%). Most counselees remained stable on outcomes: $54 \%$ on empowerment, $74 \%$ on perceived personal control and $86 \%$ on anxiety. Some counselees worsened on outcomes after the first consultation: $11 \%$ on empowerment, $9 \%$ on perceived personal control and $4 \%$ on anxiety.

After the whole genetic counselling process (T0-T2), $48 \%$ of counselees improved on empowerment, while fewer counselees improved on perceived personal control (21\%) and anxiety (17\%). Many counselees remained stable on outcomes ( $42 \%$ on empowerment, $66 \%$ on perceived personal control and $76 \%$ on anxiety). Some counselees worsened on outcomes (10\% on empowerment, $13 \%$ on perceived personal control and $7 \%$ on anxiety). Moreover, counselees who worsened in anxiety had an average score of $16(\mathrm{SD}=4)$ on the STAI at $\mathrm{T} 2$, which is considered clinically elevated anxiety.

\section{Aim 3: associations with socio-demographic and clinical variables were mostly absent}

Counselees who improved, remained stable and worsened on outcomes were compared on baseline values, sociodemographic (gender, age and education level) and clinical variables (reason for referral, type of disease and genetic test result). Only the significant associations are shown in Table 3. Tables S2-S4 (Supplementary Information) show all associations for each outcome.

\section{Baseline values}

Baseline values were significantly associated with changes on all outcomes after the first consultation (T0-T1) and after the whole genetic counselling process (T0-T2). Post hoc tests revealed that counselees who improved in empowerment, perceived personal control and anxiety had significantly worse baseline values than counselees who remained stable or worsened on both measurements. Post hoc tests also revealed that counselees who worsened in empowerment, perceived personal control and anxiety had 
Table 1 Characteristics of participants for the total sample and by reason for referral.

\begin{tabular}{|c|c|c|c|c|}
\hline & $\begin{array}{l}\text { All included } \\
\text { counselees } \\
(n=1479) \\
\end{array}$ & $\begin{array}{l}\text { Counselees with a } \\
\text { possible genetic } \\
\text { condition }(n=594)\end{array}$ & $\begin{array}{l}\text { Pre-symptomatic } \\
\text { genetic counseling } \\
(n=709)\end{array}$ & $\begin{array}{l}\text { Parents of } \\
\text { referred children } \\
(n=176)\end{array}$ \\
\hline \multicolumn{5}{|l|}{ Hospital } \\
\hline $\begin{array}{l}\text { University Medical Center } \\
\text { Groningen }\end{array}$ & $914(62 \%)$ & $384(65 \%)$ & $439(62 \%)$ & $91(52 \%)$ \\
\hline $\begin{array}{l}\text { University Medical Center } \\
\text { Utrecht }\end{array}$ & $565(38 \%)$ & $210(35 \%)$ & $270(38 \%)$ & $85(48 \%)$ \\
\hline $\mathrm{Age}^{\mathrm{a}}$ (mean, SD) & $50.8(14.8)$ & $54.2(14.0)$ & $50.7(15.2)$ & $39.1(9.4)$ \\
\hline \multicolumn{5}{|l|}{ Gender } \\
\hline Female & $1036(70.0 \%)$ & $411(69 \%)$ & $482(68 \%)$ & $143(81 \%)$ \\
\hline Male & $443(30.0 \%)$ & $183(31 \%)$ & $227(32 \%)$ & $33(19 \%)$ \\
\hline \multicolumn{5}{|l|}{ Marital status ${ }^{\mathrm{a}}$} \\
\hline $\begin{array}{l}\text { Living together without } \\
\text { children }\end{array}$ & $570(39 \%)$ & $275(47 \%)$ & $282(40 \%)$ & $13(7 \%)$ \\
\hline $\begin{array}{l}\text { Living together with } \\
\text { children }\end{array}$ & $599(41 \%)$ & $184(31 \%)$ & $274(39 \%)$ & $141(81 \%)$ \\
\hline Living alone with children & $50(3 \%)$ & $13(2 \%)$ & $29(4 \%)$ & $8(5 \%)$ \\
\hline Single & $173(12 \%)$ & $87(15 \%)$ & $81(12 \%)$ & $5(3 \%)$ \\
\hline Different situation & $79(5 \%)$ & $30(5 \%)$ & $41(6 \%)$ & $8(5 \%)$ \\
\hline \multicolumn{5}{|l|}{ Educational level $^{\mathrm{a}}$} \\
\hline $\begin{array}{l}\text { Basic (primary school, } \\
\text { secondary school, lower } \\
\text { vocational education) }\end{array}$ & $300(21 \%)$ & $130(23 \%)$ & $154(22 \%)$ & $16(9 \%)$ \\
\hline $\begin{array}{l}\text { Intermediate (middle } \\
\text { vocational education) }\end{array}$ & $570(40 \%)$ & $228(40 \%)$ & $267(39 \%)$ & $75(45 \%)$ \\
\hline $\begin{array}{l}\text { High (higher vocational } \\
\text { education, }\end{array}$ & $563(39 \%)$ & $215(37 \%)$ & $271(39 \%)$ & $77(46 \%)$ \\
\hline \multicolumn{5}{|l|}{ Employment status $^{\mathrm{a}}$} \\
\hline Working & $718(54 \%)$ & $228(43 \%)$ & $384(60 \%)$ & $106(69 \%)$ \\
\hline Studying & $37(3 \%)$ & $11(2 \%)$ & $24(4 \%)$ & $2(1 \%)$ \\
\hline Unemployed & $213(16 \%)$ & $91(17 \%)$ & $90(14 \%)$ & $32(21 \%)$ \\
\hline Unable to work (disabled) & $70(5 \%)$ & $44(8 \%)$ & $19(3 \%)$ & $7(5 \%)$ \\
\hline Retired & $249(19 \%)$ & $132(25 \%)$ & $113(18 \%)$ & $4(3 \%)$ \\
\hline Voluntary work & $35(3 \%)$ & $21(4 \%)$ & $11(2 \%)$ & $3(2 \%)$ \\
\hline \multicolumn{5}{|l|}{ Type of disease } \\
\hline Onco-genetic & $805(54 \%)$ & $373(63 \%)$ & $429(61 \%)$ & $3(2 \%)$ \\
\hline Cardio-genetic & $306(21 \%)$ & $114(19 \%)$ & $185(26 \%)$ & $7(4 \%)$ \\
\hline Neuro-genetic & $170(12 \%)$ & $54(9 \%)$ & $45(6 \%)$ & $71(40 \%)$ \\
\hline General & $198(13 \%)$ & $53(9 \%)$ & $50(7 \%)$ & $95(54 \%)$ \\
\hline \multicolumn{5}{|l|}{ After genetic testing } \\
\hline \multicolumn{5}{|l|}{ Diagnostic testing } \\
\hline Pathogenic variant & $139(27 \%)$ & $101(24 \%)$ & - & $38(42 \%)$ \\
\hline Uncertain & $25(5 \%)$ & $21(5 \%)$ & - & $4(4 \%)$ \\
\hline No pathogenic variant & $349(68 \%)$ & $300(71 \%)$ & - & $49(54 \%)$ \\
\hline \multicolumn{5}{|l|}{ Predictive testing } \\
\hline Unfavorable & $155(31 \%)$ & - & $154(31 \%)$ & $1(50 \%)$ \\
\hline Favorable & $344(69 \%)$ & - & $343(69 \%)$ & $1(50 \%)$ \\
\hline
\end{tabular}

${ }^{\mathrm{a}}$ This variable has missing values.

significantly better baseline values than counselees who remained stable and improved on both measurements.

\section{Socio-demographic variables}

Socio-demographic variables were not significantly associated with changes in outcomes. This means that age, gender and education level did not explain which counselees improved, remained stable or worsened on all outcomes, after the first consultation (T0-T1) and after the whole genetic counselling process (T0-T2).

\section{Clinical variables}

Reason for referral was significantly associated with changes in perceived personal control after the whole genetic 
Table 2 Outcomes of genetic counseling on group level.

\begin{tabular}{|c|c|c|c|c|c|c|c|c|c|}
\hline Outcome measures & Group & $N$ & $\mathrm{M}(\mathrm{SD}) \mathrm{T} 0$ & $\mathrm{M}(\mathrm{SD}) \mathrm{T} 1$ & $\mathrm{M}(\mathrm{SD}) \mathrm{T} 2$ & $p(\mathrm{~T} 0-\mathrm{T} 1)$ & $p(\mathrm{~T} 1-\mathrm{T} 2)$ & $d(\mathrm{~T} 0-\mathrm{T} 1)$ & $d(\mathrm{~T} 0-\mathrm{T} 2)$ \\
\hline \multirow[t]{4}{*}{ Empowerment } & Total sample & 1419 & 91.37 (12.17) & 95.07 (11.83) & $97.58(12.46)$ & $<.001 *$ & $<.001 *$ & 0.30 & 0.51 \\
\hline & $\begin{array}{l}\text { Genetic } \\
\text { condition }\end{array}$ & 568 & 89.81 (11.49) & 93.19 (11.86) & $95.80(12.62)$ & $<.001 *$ & $<.001 *$ & 0.29 & 0.52 \\
\hline & $\begin{array}{l}\text { Pre- } \\
\text { symptomatic }\end{array}$ & 678 & $93.21(11.93)$ & 96.97 (11.47) & 99.15 (11.94) & $<.001 *$ & $<.001 *$ & 0.32 & 0.50 \\
\hline & Children & 173 & $89.24(14.10)$ & $93.83(12.05)$ & $97.29(13.21)$ & $<.001 *$ & $<.001 *$ & 0.33 & 0.57 \\
\hline \multirow{4}{*}{$\begin{array}{l}\text { Perceived personal } \\
\text { control }\end{array}$} & Total sample & 1409 & $0.98(0.44)$ & $1.06(0.46)$ & $1.05(0.50)$ & $<.001 *$ & 0.577 & 0.18 & 0.16 \\
\hline & $\begin{array}{l}\text { Genetic } \\
\text { condition }\end{array}$ & 563 & $0.93(0.44)$ & $1.00(0.46)$ & $0.97(0.49)$ & $<.001 *$ & 0.154 & 0.16 & 0.09 \\
\hline & $\begin{array}{l}\text { Pre- } \\
\text { symptomatic }\end{array}$ & 674 & $1.03(0.46)$ & $1.11(0.46)$ & $1.09(0.51)$ & $<.001^{*}$ & 0.175 & 0.17 & 0.13 \\
\hline & Children & 172 & $0.94(0.38)$ & $1.02(0.41)$ & $1.15(0.44)$ & $.011 *$ & $<.001 *$ & 0.21 & 0.55 \\
\hline \multirow[t]{4}{*}{ Anxiety } & Total sample & 1430 & 11.64 (3.69) & $11.24(3.51)$ & $10.80(3.67)$ & $<.001 *$ & $<.001 *$ & 0.11 & 0.23 \\
\hline & $\begin{array}{l}\text { Genetic } \\
\text { condition }\end{array}$ & 579 & $12.23(3.86)$ & 11.84 (3.69) & $11.49(3.73)$ & $<.001 *$ & $.004 *$ & 0.10 & 0.19 \\
\hline & $\begin{array}{l}\text { Pre- } \\
\text { symptomatic }\end{array}$ & 682 & $10.98(3.40)$ & $10.59(3.21)$ & $10.05(3.47)$ & $<.001^{*}$ & $<.001^{*}$ & 0.11 & 0.27 \\
\hline & Children & 169 & $12.24(3.81)$ & $11.83(3.61)$ & $11.47(3.70)$ & $.046^{*}$ & 0.111 & 0.11 & 0.20 \\
\hline
\end{tabular}

$* p<.05 ; d=0.2$ small effect size, $d=0.5$ medium effect size, $d=0.8$ large effect size.

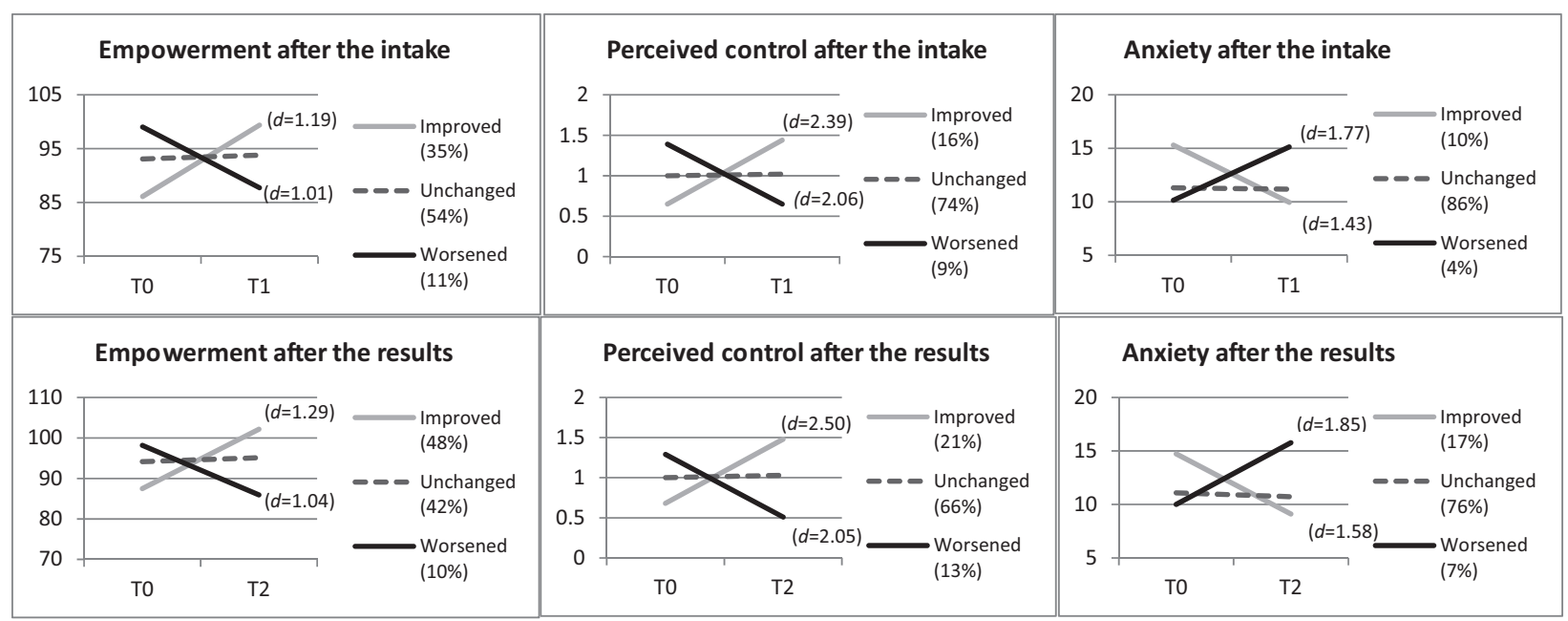

Fig. 1 Graphs with clustered individual change scores.

counselling process (T0-T2). Counselees who improved in perceived personal control were significantly more often parents of referred children than counselees with a possible genetic condition or counselees referred for presymptomatic genetic counselling. The genetic test results of counselees who were referred for predictive testing were significantly associated with changes in anxiety at $\mathrm{T} 2$. As could be expected, counselees who improved in anxiety received significantly more often a favourable genetic test result compared to counselees who remained stable or worsened. Counselees who worsened in anxiety received significantly more often an unfavourable genetic test result compared to counselees who improved or remained stable.

\section{Discussion}

In this study we examined cognitive and affective outcomes (empowerment, perceived personal control and anxiety) of genetic counselling at group and individual level in a large and heterogeneous sample of counselees. At group level, all outcomes improved after counselling, with a medium effect-size for empowerment and small effect-sizes for anxiety and perceived personal control. While empowerment and anxiety improved across the whole genetic counselling process, perceived personal control remained stable after the initial improvement seen following the first consultation. At an individual level, 
Table 3 Significant associations between change scores on outcomes and other variables.

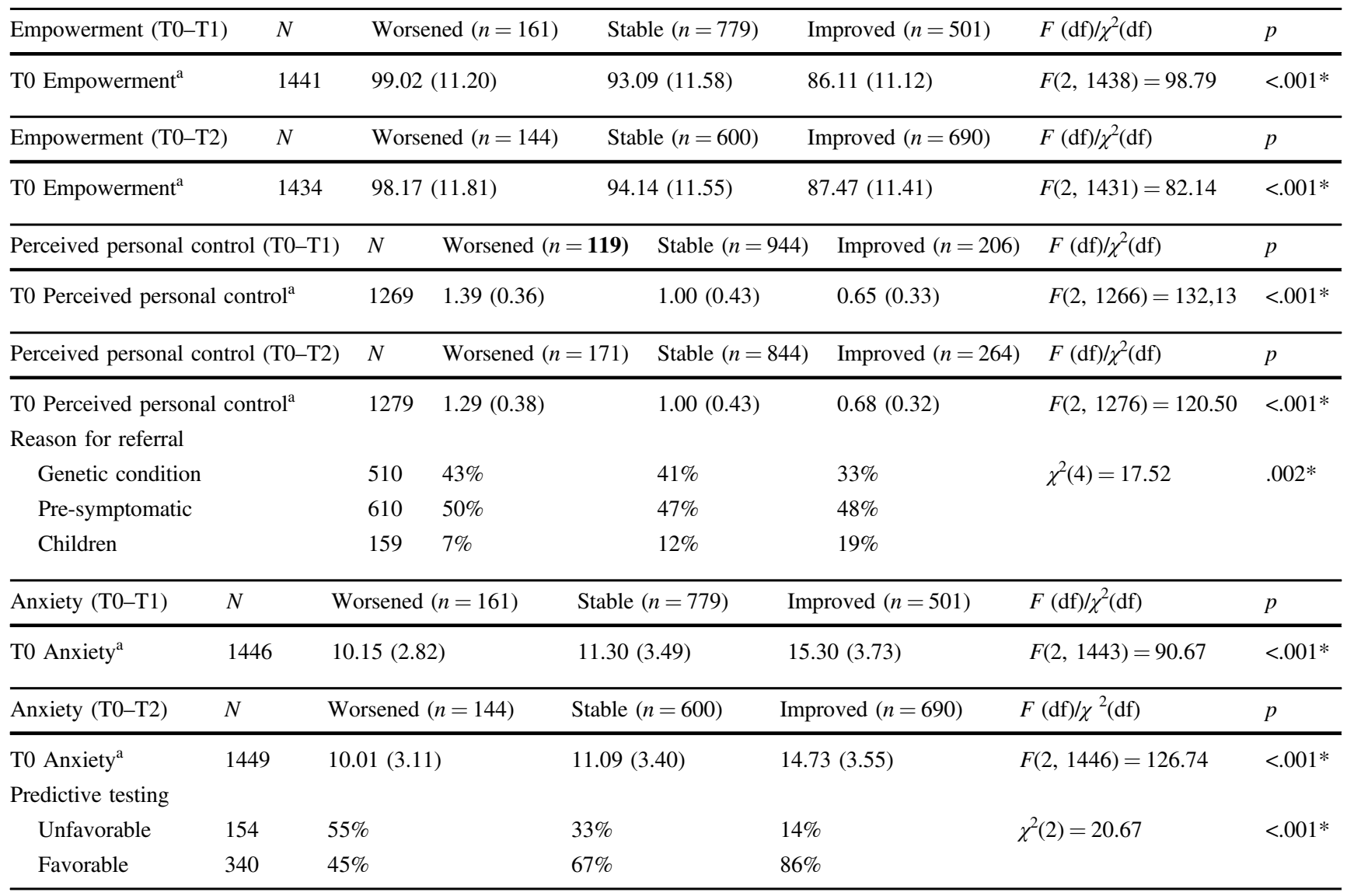

$* p<.007$.

${ }^{\mathrm{a}}$ Mean and SD.

around half $(48 \%)$ of counselees showed clinically relevant improvement on empowerment, while most counselees remained stable on perceived personal control $(66 \%)$ and anxiety (76\%). However, around $10 \%$ of the counselees showed a clinically relevant worsening on each outcome. Parents of referred children improved more often on perceived personal control than other groups. As could be expected, a favourable genetic test result was significantly associated with a decrease in anxiety, while an unfavourable genetic test result was significantly associated with an increase in anxiety. Socio-demographic variables were not associated with changes in outcomes.

That so many counselees remained stable on perceived personal control and anxiety was surprising, and such an effect has not been mentioned in other studies that have considered these outcomes [16-18]. Perhaps most counselees already experienced little anxiety and had enough personal control before and during the counselling process. An alternative explanation is how 'clinical relevant change' was operationalized. The grouping of counselees into change categories was based on a statistical norm of $0.5 \mathrm{SD}$. This means that counselees may have experienced changes in some outcome variables that they may have considered important, but these changes were smaller than this statistical norm.

Another surprising finding was that around $10 \%$ of the counselees showed a clinically relevant worsening on each outcome. Pasacreta (2003) mentioned that approximately one-quarter of counselees experience heightened levels of distress, depression and/or anxiety shortly after cancer genetic counselling and testing [19], but other systematic reviews did not mention such worsening [1-3]. The worsening of perceived personal control and empowerment have not been mentioned before. It is unclear why counselees worsened in our study, as no socio-demographical and clinical variables were associated with the decrease in perceived personal control and empowerment, and only the genetic test result was associated with anxiety. The associations with baseline values cannot be considered meaningful, as baseline values were part of the operationalization of change groups (e.g. to be considered 'improved' on empowerment, counselees needed to have much higher scores than at baseline). Eijzenga et al. also noted that sociodemographic and clinical variables do not seem particularly 
useful in identifying counselees with psychosocial problems after genetic counselling [20].

As a result of our operationalization of clinically relevant change, the worsening on outcomes in our study was strong. The question, however, is whether this worsening is a cause for concern. For anxiety, a validated cut-off score has been established to identify individuals with clinically relevant levels of anxiety. The 7\% counselees who worsened on anxiety after genetic counselling scored above this cut-off score in the final measurement, indicating clinically relevant anxiety. As the counselling process could be considered as a stressful period in which new, sometimes disturbing, medical information is communicated, it is conceivable that some counselees could worsen on outcomes even with the emotional support and knowledge provided by genetic counsellors. While negative results (e.g. being a carrier for a autosomal dominant cancer syndrome) may be frightening and lead to prolonged anxiety, the counselling apparently had not been effective enough to lower anxiety to more bearable levels for these individuals. Although cut-off scores have not yet been established for empowerment and perceived personal control, it might also be expected that counselees who worsened on these outcomes experienced insufficient perceived personal control and empowerment after genetic counselling, suggesting that counsellors had not been able to help sufficiently in these respects as well.

This study confirms that empowerment, as measured by the GCOS-18, could be considered a valuable outcome in genetic counselling [8]. The GCOS-18 appears capable of measuring the goals of genetic counselling and changes in cognitive and affective outcomes over time, as we found in our previous research [9]. New large outcome studies and more qualitative research is necessary to determine what could be considered normal and desirable effect-sizes on outcomes of genetic counselling and to understand more about the counselees who worsen on outcomes during the genetic counselling process. Recently a minimum clinically important difference for the GCOS-24 was established of 10.3 points [21]. Although this norm could be expected to be lower for the shorter version of the GCOS-18, the counselees who improved in our sample have reached this norm with 13.3 (T0-T1) and 14.7 (T0-T2) points.

In addition to being outcome measures of genetic counselling, the PROMs in this study may also be valuable as screening instruments to clarify counselees' needs before genetic counselling and as process measures to identify which counselees have not gained sufficient knowledge or may have emotional problems during and after genetic counselling. To use PROMs for such purposes, routine outcome monitoring of the counselling process is necessary. This means offering questionnaires to counselees before genetic counselling starts and after each counselling session, and acting on these outcomes during the counselling process. Previous research already showed that routine outcome monitoring of psychosocial problems by PROMs in genetic counselling for cancer and psychiatric disorders facilitates genetic counsellors' recognition and discussion of their clients' psychosocial problems and reduces clients' distress levels [22], and describes how such procedures could be implemented in clinical practice [23].

Another focus for future research could be exploring subgroups among counselees based on cognitive and affective outcomes. Subgroups are possible to recover from observed data by latent variable models, such as latent class analysis (LCA) and latent profile analysis (LPA). As differences in change among counselees were insufficiently explainable by clinical and socio-demographic variables, such analyses may provide new insights why counselees differ in outcomes after genetic counselling.

\section{Strengths and limitations}

The strengths of our study include the multicenter approach and the large and diverse study sample, which included different type of counselees, different categories of genetic conditions and different reasons for genetic consultations. Another strength is our use of cognitive as well as affective outcomes, all of them measured at multiple time points in the whole genetic counselling process. There were also some limitations. Of the 2502 participants, 1023 participants had to be excluded because they did not complete all the questionnaires. A comparison between the included participants and all respondents showed significant differences in age and reason for referral. These differences were not considered to be confounders because all outcomes did not differ significantly between these groups at T0. Only a small part of our sample consisted of parents of referred children. More research seems necessary to understand more about this particular subgroup, especially as this subgroup may have other concerns and needs regarding genetic counselling (e.g. prognosis of the child, family planning, parental responsibility, concerns about culpability). Our sample consisted of counselees who were competent with the Dutch language. The outcomes of genetic counselling for counselees who are less competent with the Dutch language are therefore unknown. The third measurement (T2) was performed within 1 week after results of genetic counselling were discussed, from which we know from literature on predictive genetic testing, may be a transient initial period of distress. Furthermore, because this research consists of a pre-post observational design, causal inferences are less convincing compared to clinical trials.

To conclude, this study demonstrated improvements among counselees in cognitive and affective outcomes after genetic counselling at group level, which is in line with the pre-formulated and professionally widely supported goals 
of genetic counselling. However, our results also suggest that there are opportunities for improvement at individual level, as many counselees remained stable and some even worsened on all outcomes. Routine outcome monitoring could help to explore the needs of counselees before and during the genetic counselling process and could help to identify counselees who worsen. Routine outcome monitoring could also identify individuals who may need less counselling because they already feel well-informed and experience no emotional distress and whose needs may sufficiently met by, for instance, digital information and/or decision-aids. Future research could therefore focus on the GCOS-18 as a useful screening instrument and process measure for the genetic counselling process.

Acknowledgements We thank all the research assistants for the collection and input of the data. We thank all counselees and genetic counsellors who participated in our study. We thank Kate Mc Intyre for editing our paper.

\section{Compliance with ethical standards}

Conflict of interest The authors declare that they have no conflict of interest.

Publisher's note Springer Nature remains neutral with regard to jurisdictional claims in published maps and institutional affiliations.

\section{References}

1. Braithwate D, Emery J, Walter F, Prevost AT, Sutton S. Psychological impact of genetic counseling for familial cancer: a systematic review and meta-analysis. Fam Cancer. 2006;5:61-75.

2. Madlensky L, Trepanier AM, Cragun D, Lerner B, Shannon KM, Zierhut H. A rapid systematic review of outcomes studies in genetic counseling. J Genet Couns. 2017;26:361-78.

3. Athens BA, Caldwell SL, Umstead KL, Connors PD, Brenna E, Biesecker BB. A systematic review of randomized controlled trials to assess outcomes of genetic counseling. J Genet Couns. 2017;26:902-33.

4. Resta R, Biesecker BB, Bennett RL, Blum S, Hahn SE, Strecker $\mathrm{MN}$, et al. A new definition of Genetic Counseling: National Society of Genetic Counselors' Task Force report. J Genet Couns. 2006;15:77-83.

5. Bernhardt BA, Biesecker BB, Mastromarino CL. Goals, benefits, and outcomes of genetic counseling: client and genetic counselor assessment. Am J Med Genet. 2000;94:189-97.

6. Biesecker BB. Goals of genetic counseling. Clin Genet. 2001;60: 323-30.

7. McAllister M, Wood AM, Dunn G, Shiloh S, Todd C. The Genetic Counseling Outcome Scale: a new patient-reported outcome measure for clinical genetics services. Clin Genet. 2011;79:413-24.
8. McAllister M, Dearing A. Patient reported outcomes and patient empowerment in clinical genetics services. Clin Genet. 2015;88:114-21.

9. Voorwinden JS, Plantinga M, Krijnen W, Ausems M, Knoers N, Velthuizen M, et al. A validated PROM in genetic counselling: the psychometric properties of the Dutch version of the Genetic Counselling Outcome Scale. Eur J Hum Genet. 2019;27:681-90.

10. Plon SE, Eccles DM, Easton D, Foulkes WD, Genuardi M, Greenblatt MS, et al. Sequence variant classification and reporting: recommendations for improving the interpretation of cancer susceptibility genetic test results. Hum Mutat. 2008;29:1282-91.

11. Smets EM, Pieterse AH, Aalfs CM, Ausems MG, van Dulmen AM. The Perceived Personal Control (PPC) questionnaire as an outcome of genetic counseling: reliability and validity of the instrument. Am J Med Genet A. 2006;140:843-50.

12. Van der Bij AK, de Weerd S, Cikot RJ, Steegers EA, Braspenning JC. Validation of the Dutch short form of the state scale of the Spielberger State-Trait Anxiety Inventory: considerations for usage in screening outcomes. Community Genet. 2003;6:84-7.

13. Annema C, Roodbol PF, Van den Heuvel ER, Metselaar HJ, Van Hoek B, Porte RJ, et al. Trajectories of anxiety and depression in liver transplant candidates during the waiting-list period. $\mathrm{Br} \mathrm{J}$ Health Psychol. 2017;22:481-501.

14. Cohen J. Statistical Power Analysis for the Behavioral Sciences. 2nd edn. New York: Academic Press; 1988.

15. Norman G, Sloan J, Wyrwich K. Interpretation of changes in health-related quality of life: the remarkable universality of half a standard deviation. Med Care. 2003;41:582-92.

16. Randall J, Butow P, Kirk J, Tucker K. Psychological impact of genetic counselling and testing in women previously diagnosed with breast cancer. Intern Med J. 2001;31:397-405.

17. Otten E, Birnie E, Ranchor AV, van Tintelen JP, van Langen IM. A group approach to genetic counselling of cardiomyopathy patients: satisfaction and psychological outcomes sufficient for further implementation. Eur J Hum Genet. 2015;23:1462-7.

18. Rothwell E, Kohlmann W, Jasperson K, Gammon A, Wong B, Kinney A. Patient outcomes associated with group and individual genetic counseling formats. Fam Cancer. 2012;11:97-106.

19. Pasacreta JV. Psychosocial issues associated with genetic testing for breast and ovarian cancer risk: an integrative review. Cancer Invest. 2003;21:588-623.

20. Eijzenga W, Bleiker EMA, Hahn DEE, Van der Kolk LE, Sidharta GN, Aaronson NK. Prevalence and detection of psychosocial problems in cancer genetic counseling. Fam Cancer. 2015;14: 629-36.

21. Thomas C, McAllister M. Establishing the minimum clinically important difference for the Genetic Counseling Outcome Scale (GCOS-24). J Genet Couns. 2019;28:1003-10.

22. Eijzenga W, Aaronson NK, Hahn DEE, Sidharta GN, van der Kolk LE, Velthuizen ME, et al. Effect of routine assessment of specific psychosocial problems on personalized communication, counselors' awareness, and distress levels in cancer genetic counseling practice: a randomized controlled trial. J Clin Oncol. 2014;27:2998-3004.

23. Austin JC. Evidence-based genetic counseling for psychiatric disorders: a road map. Cold Spring Harb Perspect Med. 2019. https://doi.org/10.1101/cshperspect.a036608. 